\title{
Does the Syntax of Modern Persian Allow the locative Verbs to Participate in Alternation?
}

\author{
Masoume Yakhabi (Corresponding author) \\ Islamic Azad University- Isfahan (Khorasgan) Branch, Iran \\ E-mail:Yakhabimy@yahoo.com \\ Ahmadreza Lotfi \\ Islamic Azad University- Isfahan (Khorasgan) Branch, Iran \\ E-mail: lotfi.Ahmadreza@gmail.com
}

\author{
Received: 09-03-2017 \\ Accepted: 17-05-2017 \\ Advance Access Published: July 2017 \\ Published: 01-09-2017 \\ doi:10.7575/aiac.ijalel.v.6n.5p.255 \\ URL: http://dx.doi.org/10.7575/aiac.ijalel.v.6n.5p.255
}

\begin{abstract}
Some locative verbs enjoy the possibility of appearing in more than one syntactic pattern. There is, however, controversy on whether locative verbs in modern Persian can participate in alternation or not. The aim of the present paper is to investigate the issue, analyzing basic syntactic word order of double object constructions in Persian, syntactic and semantic features of specific and nonspecific objects in Persian and syntactic word formation process. The point that the basic word order in Persian allows only one thematic object (either specific or non-specific object) and the fact that the non-specific objects in double object constructions can join the verb and create one syntactic and semantic unit that saturates one argument position, all indicate that locative verbs cannot alternate in this language. The main argument here is that when the non-specific object joins the verb, it becomes a part of the verb and is not anymore a participant in the action of the verb. All the evidence provided are in favor of the absence of alternating locative verbs in Persian.
\end{abstract}

Keywords: locative verbs, specific object, bare object, alternation, non specific object

\section{Introduction}

One of the most commonly used sentence patterns in human languages, attracting so many linguists is Double Object Construction (DOC). Double object verbs are predicates which select a noun phrase (NP) to fill the specifier position and two nouns to act as the direct and indirect objects. Locative constructions are one type of such double object constructions. As stated by Bley-Vroman and Joo (2001), involving various cognitive-linguistic concepts such as changing states, moving objects and being affected is what has made the syntax of locative constructions so interesting for linguists.

Olbishevska (2005) defines locative verbs as verbs that involve transfer of an object, material, or set of objects into/onto or from a container or surface. Goal, Ground, or Location are different labels referring to the entity into/onto or from which the object or substance is moved. Theme, Figure, or Locatum are different names used to refer to the entity being transferred. A locative verb belongs to figure-oriented class if it maps its theme onto the direct object position and its locative argument is realized as the complement of a locative preposition like into/onto or from (she dribbled paint onto the floor/* she dribbled the floor with paint). A locative verb, however, would be classified in ground-oriented class if its theme position is occupied by a prepositional phrase headed by the preposition with and the direct object position is filled by the locative argument (she soaked the sponge with water/* she soaked water into the sponge) (Olbishevska, 2005).

What is especially significant about locative constructions is that they can participate in alternation. Some locative verbs, as triadic verbs, have the capacity to set the same set of their internal arguments in more than one way, creating two argument realization patterns which are felt to be near paraphrases, for instance Tom loaded the apples onto the truck/Tom loaded the truck with apples. The so-called locative alternation represents one instantiation of the larger phenomenon of multiple argument realization (Levin and Rappaport, 2005). However, all of the locative verbs cannot participate in alternation. Verbs which denote only either the motion (e.g. pour) or the final state (e.g. fill) do not alternate. On the other hand, verbs that in some manner focus both on motion and the resulting state do alternate.

Although some of these verb alternations are common in several languages, they are not universal. Alternation in the verb argument structure is a language-specific phenomenon, meaning that these alternations are different from language to language and each language has its own system, including a number of important alternations. In a cross- linguistic survey by Kim (1999), it is revealed that how different languages are with respect to locative alternation. For instance, the verb load alternates in some languages (English, Italian, Hebrew, Malay), but in other languages just the objective 
variant of this verb is allowed (Chinese, Thai, Japanese, and Korean). The results of Kim's investigation further reveals that other verbs categorized under load/spray class, however, do not behave the same in all languages: for example, in some languages such as Hebrew and Turkish, the verb spray is just allowed to be used in its objective variant, while load can alternate. On the other hand, in languages such as Chinese and Thai, the verb spray alternates while load is grammatical only if it is used in its objective frame (Kim, 1999, 145). This example can well show how different locative alternation is across languages. The main purpose of this study is to determine if Persian locative verbs can participate in alternation and if not what prevents them from appearing in more than one syntactic pattern?

One of the questions raised by scholars working on locative verbs is what properties of verbs determine whether they can occur in figure-frame, the ground-frame, or both as well as what properties permit the alternation. The general hypotheses of the argument projection concern with the issue of whether argument expression is aspectually driven, or if argument expression is lexically or syntactically determined. Among various accounts of locative alternation three main types of theories have been extensively discussed, that can be referred to as thematic role account, aspectual account, and syntactic account (Olbishevska, 2005).

The thematic and aspectual approaches consider lexical level as the initial level at which lexical properties of the verb are identified and then some of that lexical information becomes visible at the level of syntax through either an intermediate level of PAS (Levin and Rappaport, 1988) or aspectual properties (Tenny, 1987). Based on these approaches the difference between the two variants of the alternating locative verbs is originated from lexicon, not syntax. The proponents of these approaches would argue that the semantic difference between the two variants actually corresponds to the existence of two different predicates in the lexicon, named by the same verb. The independent projection of these predicates onto syntax through highly specific linking rules then creates the two variants of the locative verb (Damonte,1997). Pinker (1989) also suggests that the difference in the syntactic realization of the locative verb arguments is a by-product of the difference between two distinct semantic representations of the same verb that then each of them would independently create a variant of the locative verb.

The syntactic approach, advocated by Borer (1994), Van Hout (1996), Goldberg (1995), suggests syntax to be the determiner of verb's semantic properties. It denies rich lexical specifications and linking rules by suggesting that the verb arguments do not possess any specifications in the lexicon, and the verbs are specified only as to the number of their arguments. The arguments acquire their agent or patient related properties once they are placed in the syntactic positions associated with such properties; syntactic positions themselves provide semantic interpretations to the arguments. Locative verbs are listed as verbs with three unspecified arguments which are then mapped into the already existing argument positions of the verb.

\section{Statement of the Problem}

English locative verbs have been studied in depth and from different perspectives. A great deal of research has been done on locative alternation in English language. As the result, there exists detailed information regarding how many English locative verbs exist in English, and which of them can participate in alternation, which ones are non-alternating figure verb, and which ones are non-alternating ground verbs. Unlike English, Persian locative verbs and their alternation possibilities have devoted just a very limited number of studies to themselves. There is even a lack of agreement among researchers on whether these verbs can alternate in Persian or not. Modern Persian is an Eastern IndoIranian branch of Indo-European language family. The dialect of modern Persian we examine in this study is the standard colloquial dialect spoken in Iran called Tehrani. The term Persian is used to refer to this variant throughout this study.

\section{Design of the study}

This paper is organized as follows. In the first section different proposals on Persian locative verbs and their classifications are presented. This part exhibits the conflicting points of view among the community studying Persian locative verbs and the possibility of their alternations. In the next part, the authors of the paper will try to show that locative verbs cannot alternate in Persian, providing an analysis of Persian basic syntactic word order and syntactic word formation process in this language. In this part, a concise comparison is also made between English and Persian locatives. The discussion is then followed by the conclusion and summary of the results.

\section{Different views on the alternation of Persian locative verbs}

As mentioned in the previous section, there is not consensus among scholars on the possibility of alternation of Persian locative verbs. In this part of the study some presented views are surveyed.

As the first classification, Roshan (1998) categorizes the Persian locative verbs to the two groups of placing and removing locative verbs. He further classifies the placing and removing verbs to the subclasses of alternating and nonalternating placing verbs, and alternating and non-alternating removing verbs:

1. Alternating placing verbs: such as pašidan (splash), bar zadan (load), and kaštan (plant)

2. Non-alternating placing verbs: such as čhapandan (jam), anbaštan (cram).

3. Alternating removing verbs like: such as tamiz kardan (clean).

4. Non alternating removing verbs: such as zoduodan 
Rezai and Avand (2008), however, believe that in Persian just the non-alternating forms exist. They believe that (compared to English) Persian system seems to be more restricted in the case of narrow-range constraints. The locative structures in Persian are comprised of just non-alternating constructions where as some English counterparts involve alternating forms, too. The classification they have presented for Persian locative verbs is as follows:

1. Non-alternating figure verbs: such as rixtan (pour), čekandan (dribble), kešidan (paint), allow the figure (theme argument) but not the ground (goal argument) to be located in the direct object position.

2. Non-alternating ground verbs: such as bar kardan (load), por kardan (fill), taziin kardan (decorate), xis kardan (soak) permit the goal argument but not the theme argument to be realized as the direct object.

Rezai and Avand (2008), however, provide no evidence for why they believe that locative constructions cannot alternate in Persian. This is the question that this paper mainly aims to investigate, using the basic syntactic structures in Persian.

On the other hand, following Roshan (1998), Karimi Doostan and Safari (2011), believe that alternating locative verbs also exist in Persian. They believe that in Persian a number of verbs denoting dislocation of a substance (locatum) to a surface or a container (location) participate in locative alternation (e.g., bar zadan 'load', pashidan 'spatter'). The locative alternation in Persian denotes the specific relationship between the two possible syntactic realizations of the verb phrase (VP) internal arguments of the same verb, called the locative variant and the objective variant. In locative variant the locatum is realized as noun phrase (NP) accompanied by "ra" and location as a prepositional phrase (Prep P). In objective variant the location argument appears as NP accompanied by "ra" and locatum as a bare NP just before the verb.

In fact, in the case of Persian locative alternating verbs, while the syntactic structure of the locative variant (sentence 1a) is similar to its English counterpart, the syntactic behavior of the objective variant (sentence 1b) is different from its with variant counterpart in English. The following model represents an example of an alternating figure verb in Persian as stated by Karimi Doostan and Safari (2011) with its English counterpart shown in front of it:

(1)

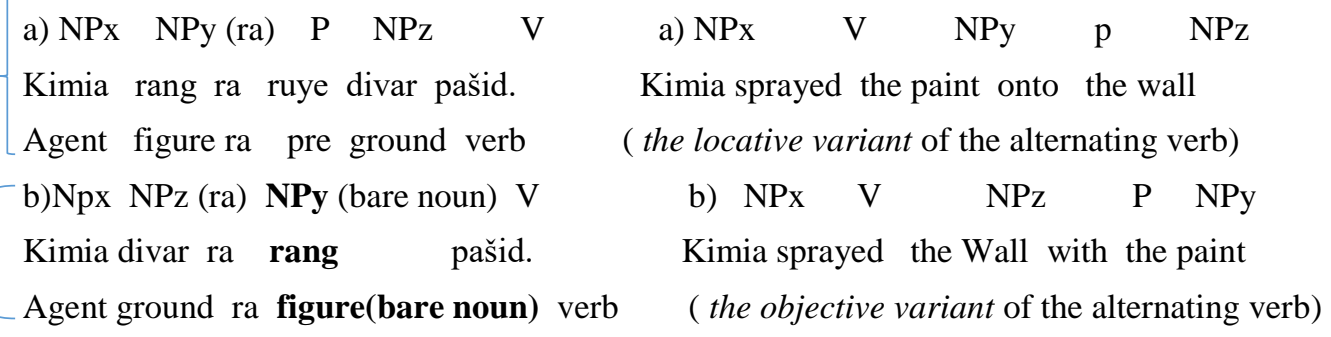

They believe non-alternating locative verbs in Persian, however, to have a syntactic structure similar to English that can be represented as follows by $2 \mathrm{a}$ and $2 \mathrm{~b}$ sentences respectively:

(2)

a) NPx NPy (ra) $\mathrm{PNPz}$
Sara lebas ra dar chamadan chapand.

b) $\mathrm{NPx} \mathrm{NPz}+(\mathrm{ra})$ PNPy $\mathrm{V}$
Sara miz ra ba rumizi pushand.
agent ground prep figure verb

$(\mathrm{NPx}=$ agent $\quad \mathrm{NPy}=$ figure $\quad \mathrm{NPz}=$ ground $) \quad$ (Karimi Doostan $\&$ Safari, 2011).

If such a view comes to be true, all four syntactic subclasses of locative verbs existing in English, there also exist in Persian. However, the specific verbs categorized under each subclass in Persian may belong to another subclass in English. For example, "tudekardan" "pile" that is a non-alternating figure verb in Persian, is classified as one of the members of alternating figure verbs in English, or "chapandan" 'stuff" that is classified as a non-alternating figure verb in Persian, belongs to the alternating ground verbs in English. The classification of locative verbs in Persian as presented by Karimi Doostan and Safari (2011) is as follows: 
1 Non-alternating Figure verbs (e.g., "chapandan" "stuff", "tazrigh kardan" "inject") the Figure but not the Ground is allowed to be mapped to the direct object position.

2 Non-alternating Ground verbs (e.g., "pushandan" "cover", "por kardan" "fill”) Ground, but not the Figure is allowed to be licensed as the direct object.

3 Alternating Figure verbs (e.g., pashidan" "spray", "kashtan' "plant") both the Figure and the Ground are allowed to fill the direct object position.

4 Alternating Ground verbs (e.g., "barzadan' "load", "chasbandan" "paste up") both the Ground and the Figure are allowed to occupy the direct object position.

\section{Evidence in favor of impossibility of locative alternation in Persian syntax}

In the rest of the study, the writers would provide evidence rejecting the existence of such a variant of locative constructions in Persian, basing their claim upon Persian basic word order of double object constructions and word formation process

Basic word order in Persian and the syntactic word formation process

In order to capture the real character of a language, we have to look deeply into the syntactic facts of that language. Since the study of syntax in a language is closely related to the basic word order of that language, we have to know the basic word order in Persian first. Karimi (2005) presents the basic word order in Persian with respect to the verb and its phrasal arguments. Persian is a verb final language whose unmarked word order in double object constructions is as follows:

$$
\left\{\begin{array}{llll}
\text { a. }(\mathrm{S}) & (\mathrm{O}+\mathrm{ra}) & (\mathrm{PP}) & \mathrm{V} \\
\text { b. }(\mathrm{S}) & (\mathrm{PP}) & (\mathrm{O}) & \mathrm{V}
\end{array}\right.
$$

(a) shows a sentence with a direct object marked by ra, the case marker for specific objects. PP represents the position occupied by any subcategorized prepositional phrase. $\underline{\mathrm{O}}$ in (b) stands for a nonspecific object. Persian allows only one thematic object. Thus $\underline{\mathrm{O}+\mathrm{ra}}$ (specific object) and the bare $\underline{\mathrm{O}}$ (nonspecific object) cannot both appear in a given sentence. It is this fact about Persian basic word order that we base our argument upon it.

Karimi (2005) presents a full explanation of syntactic and semantic features of what she calls specific and nonspecific objects in Persian. She presents the following syntactic, semantic, and morphological asymmetries distinguishing the specific objects from the nonspecific objects. As these features are closely related to our topic of discussion, they are presented below:

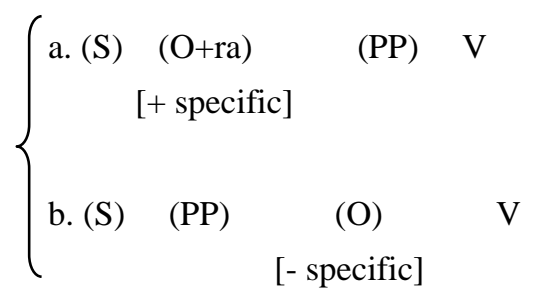

Syntactic asymmetries:

a. It is possible for specific objects to bind the indirect object; while this is not the case for nonspecific objects.

b. Nonspecific objects can only occupy the syntactic position preceding the verb (or the nonverbal element within a complex predicate), and be adjacent to it; specific objects are not restricted by this adjacency principle.

c. Specific and nonspecific objects cannot simultaneously occupy the argument positions in a coordination construction.

Morphological asymmetry

Nonspecific objects can go through a process of lexicalization (through compounding with the verb); specific objects do not.

\section{Semantic asymmetries}

a. Nonspecific objects as a part of predicate are also involved in the description of the predicate; specific objects are not.

b. There exists compatibility between nonspecific objects and adverbs indicating process; specific objects are, however, compatible with adverbs denoting accomplishment.

c. When scrambled, specific objects enter scope interaction; nonspecific objects do not. 
Taking into consideration all of these properties of specific and non-specific objects, it can be said that Persian basic syntactic word order does not allow the creation of what has been called by Karimi Doostan and Safari (2012) as the with variant of locative verbs in Persian. This variant includes both specific and non-specific objects in one structure and this is not allowed by Persian basic syntactic word order. This fact is shown in sentence number 4:

(4)

a) *Npx NPz (ra) NPy (bare noun) V ( The Persian counterpart of with variant in alternating verbs)

Kimia divar ra rang pašid.

Subject specific obj nonspecific obj verb

As it is not allowed in Persian to have both specific and non-specific objects in one construction, this sentence is not considered as a grammatical sentence in Persian. Moreover, most Persian speakers do not use this second form of locative verb proposed by Karimi Doostan and safari (2012). Such constructions are very rare in colloquial Persian and are considered to be marked.

According to Kim (1999), what blocks the way to the with variant of alternating locative verbs to appear in some languages like Chinese is the fact that in these languages preposition does not incorporate onto the verb and consequently the locative argument cannot get structural case. In such languages, instead, what is called by Kim (1999) as "serializing strategy" occurs. Kim defines this strategy as serial verb constructions or verb compounding. This verb compounding that results in the creation of serial verb constructions seems to be what occurs in Persian as 3(a) and 3(b) above. Such sentences ( $3 a$ and $3 b$ ) as claimed by Kim are serial verb constructions, not the two variants of a locative verb. This non-semantic reason proposed by Kim (1999) to account for the absence of with variant of alternating locative verbs in a given language seems to be also applicable to Persian.

In a study conducted by Lotfi and Yakhabi (M.S) a group of 80 Persian university students studying different fields of study are asked to describe in Persian (their native language) 50 pictures including a locative verb, a subject, and two objects. The purpose is to investigate what locative structures (figure, ground, or alternating) Persian native speakers use for each verb and if Persian native speakers alternate locative verbs in their native language or not. The results of the study reveal that the pictures are described in one or both of the following forms:

(5)

a) Ali daru ra be bimar tazrigh kard.

b) Ali be bimar daru tazrigh kard.

These two forms are the two basic word orders allowed for double-object verbs in Persian. In the rest of this study, however, we will show that although both of these structures are grammatical and used frequently in colloquial Persian, the second variant (sentence b) cannot be regarded as a variant of the locative verb. The upcoming information helps to prove such a claim.

The nonspecific object is in many aspects similar to the nonverbal element of a complex verb. Persian possesses a growing number of complex verbs made of a light verb and a non-verbal element (Mohammad and Karimi, 1992; among others). Although there exists differences between constructions with complex verbs and predicates consisting of a non-specific object and a real verb, they share a set of similarities. For example, the non-verbal element of the complex verb is created in a syntactic position next to the light verb, forming a semantic unit with it. Furthermore, the non-verbal element and the nominalized light verb can make up a compound noun. The same fact is true of non-specific object and the verb.

In order to account for the special relation between the verb and its non-specific object, Karimi (2003) adopts a version of distributed morphology (DM) (Halle and Marantz, 1993) developed by Marantz (1997), which is closely related to our discussion. In this framework, three different lists are recognized as follows:

List 1

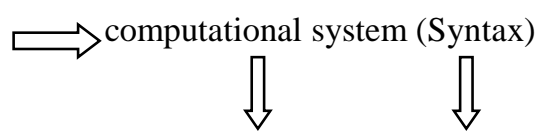

List $2 \longrightarrow$ phonology

LF

Phonetic Interface Semantic Interface

List3

List 1 contains the narrow lexicon that the syntax operates on. List 2 consists of the vocabulary that determines the connection between terminal nodes from the syntax and their phonological realizations. List 3 is called the encyclopedia and consists of complex elements denoting special meanings. This is the last list that is mainly related to the topic of this study. The encyclopedia is the locus of the semantic knowledge. The idea is that special sound and special meaning do not coincide inside the word, and thus encyclopedic knowledge is not part of the computational system at the point of enumeration where lexical information is mapped onto syntax. The claim is that the domain of the encyclopedic knowledge is the phrase rather than the word. 
Karimi (2003) calls the process that creates this encyclopedic domain Syntactic Word Formation (SWF), and suggests $\mathrm{V}^{\prime}$ to be the structural domain where the encyclopedic knowledge consisting of the special meaning of the verb and its modifiers is obtained. This is stated as follows:

$\left\{\begin{array}{l}\text { The Domain of Syntactic Word Formation (SWF) } \\ V^{\prime} \text { is the domain of SWF that operates on DP-V, and provides the encyclopedic knowledge. }\end{array}\right.$

Returning to Persian non-specific objects, we saw that their semantic, syntactic, and morphological properties suggest the existence of a special bond between them and the verb they appear with. Semantically the verb and its non-specific object provide a special meaning that cannot be produced directly by the lexicon, and is obtained in syntax within the domain of SWF. Within this domain the special meaning of complex elements build up in a binary format between elements that enter a sisterhood relation. If we consider the following configuration, CV stands for complex verb consisting of a light verb and a non verbal element:

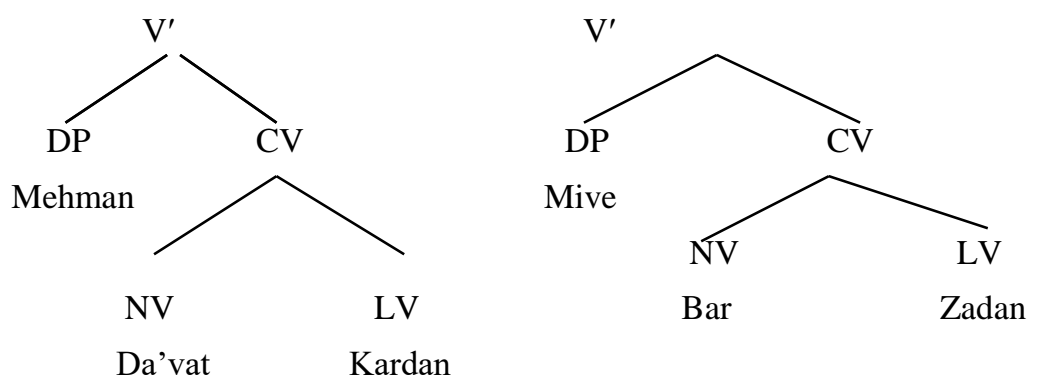

The light verb (LV) kardan and zadan "to do" is syntactically, and thus semantically, closer to the non-verbal elements (NV), Da'vat "invitation" and bar "loading" than the non-specific objects mehman "guest' and mive "fruit". Therefore, LV combines with the NV and provides not only the semantic concepts to invite and to load, but also the special event and the argument structure of the whole CV. The next syntactic word formation, and thus semantic fusion, applies between the complex verb and its sister, the non-specific object, creating one syntactic and semantic unit. This operation saturates one argument position, and the result has the effect of [N+ Ving] interpretation. SWF not only accounts for the compounding facts as well as the binding and adjacency constraints, but also it explains why the nonspecific object is part of the event, and therefore, cannot be a participant in the event (Karimi, 2003).

The specific object, however, as the argument of the verb that undergoes the event expressed by the verb, must occupy a higher position than $\mathrm{V}^{\prime}$ in order to escape SWF. The following Phrase Structure Rule Summarizes the differences between specific and non-specific objects as explained above:

(6)

$$
\text { a. [vp DP }{ }_{\text {[+specific] }}\left[v^{\prime}\right. \text { PP V]] }
$$

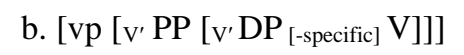

Taking into consideration the Syntactic Word Formation (SWF) process in Persian, we can come to the conclusion that those constructions in which the non-specific object is joined to the complex verb creating one syntactic unit are not an instance of locative constructions. Since for a construction to be considered as locative, it should not only contain a location and a locatum argument, but also both of these arguments should be a participant in the event, and not part of the event. Since in constructions where non-specific object is adjacent to the complex verb, the non-specific object undergoes word syntactic formation process and creates one syntactic and semantic unit that saturates one argument position, therefore in such constructions only one of the arguments participates in the event and the other one is just part of the event. Such Persian constructions include only one argument (location) that participates in the event and the other one (locatum) has become a part of the event.

Having in mind the above explanations, we will consider the example sentences with an indirect and a non-specific object that may be regarded as the second form of locative construction in Persian and then will show that despite of being grammatical, they cannot be either considered as a variant of locative construction in Persian:

(7)

$\left\{\begin{array}{l}\text { (a) Kimia miveha ra tuye kamiun barzad } \\ \text { Kimia fruit Pl ra into the truck loaded } \\ \text { "Kimia loaded the fruits into the truck" } \\ \text { (b) Kimia tuye kamiun mive bar zad } \\ \text { Kimia in truck fruit loaded } \\ \text { "Kimia loaded the truck with fruits" }\end{array}\right.$ 
The specific object followed by the specificity marker $-r a$ is the particular individual that undergoes the event described by the verb (Karimi, 2005). In locative constructions, however, both the location and locatum (direct and indirect object) undergo the action of the verb and are therefore participants in the event. In sentence (a), which is an instance of locative construction, both the specific object $(\mathrm{O})$ and the object of preposition (PP) undergo the action of the verb. Consequently, the sentence (a) would be the most natural answer to the following questions:

\section{Where did Kimia load the fruit? And}

What did Kimia load into the truck?

In contrast, the nonspecific object is part of the event, rather than the participant in the event. That is, it creates an abstract semantic unit with the verb describing the event or the state. Therefore, it is part of the description of the predicate (Karimi, 2005). The sentence (b) is, therefore, not an instance of locative construction, as just the direct specific object undergoes the action of the verb in this sentence, while non-specific object (used as a bare noun) becomes a part of the event of the verb. Therefore, sentence (b) would be the most natural answer to the following questions:

What did Kimia load with the fruit? And

\section{What did Kimia do?}

As it can be observed, in sentence (a) the locative verb load has two internal arguments that both of them participate in the event, as it is apparent from the type of questions asked. However, in sentence (b), the verb load has just one argument that participates in the event (location, the truck), while the other one (locatum, the fruits) has become a part of the complex predicate that together saturate the argument position as a single syntactic and semantic unit and, thus, it is no more an internal, independent argument to participate in the event of the verb. The question "What did Kimia do?" is an indication of this fact, showing that the locatum has become a part of the event. Therefore, sentences such as (b) are not a kind of locative construction, since, as stated before, locative constructions have two internal objects that both of them participate in the event.

Representing another sentence in the form of three diagrams can help to better clarify the point.
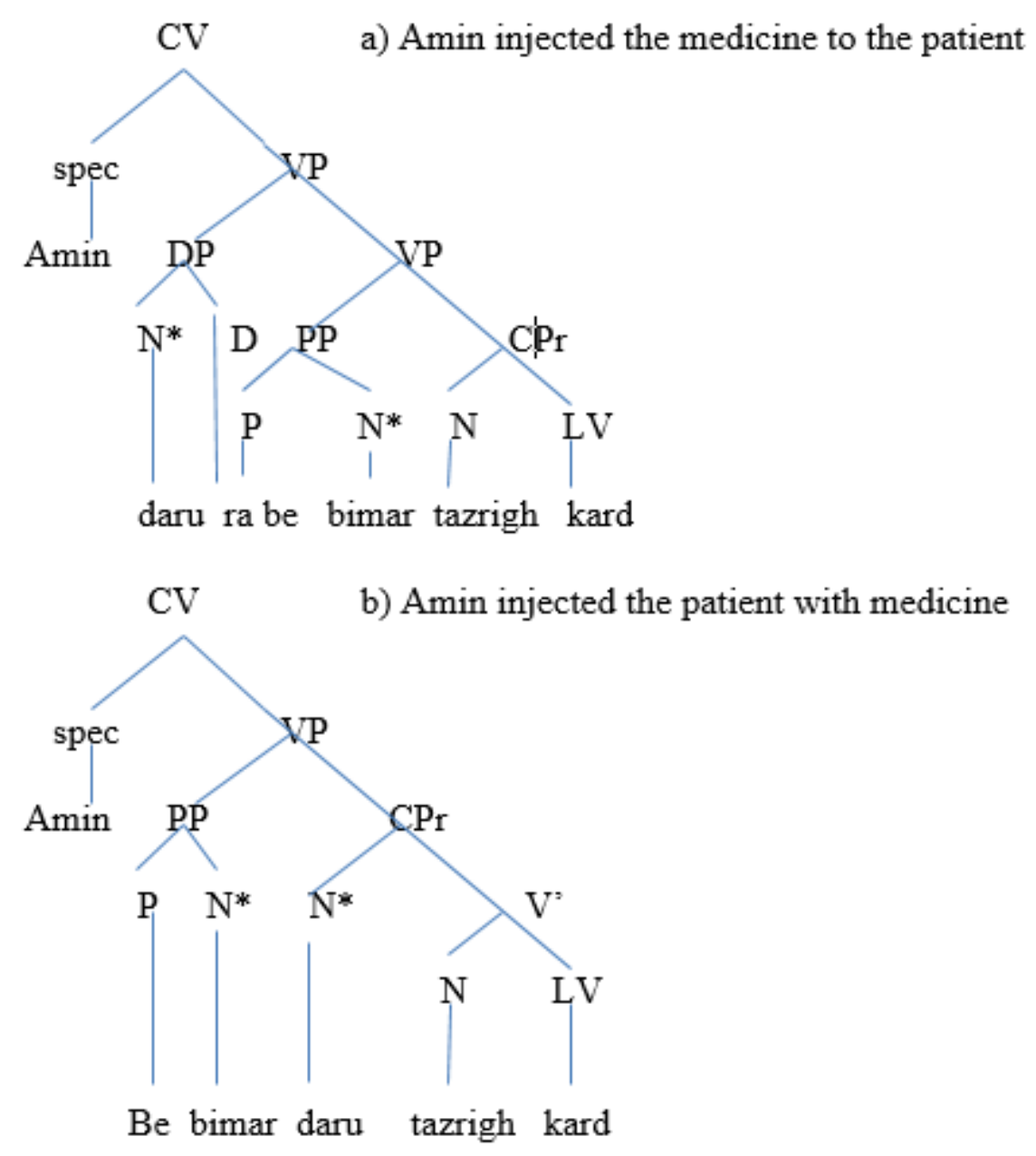
In sentence (a) there are two nouns shown by asterisks (N): the first one from the left is the specific object that precedes the indirect object and is followed by ra. The second one is the indirect object that is immediately c-commanded by PP. both of these objects can participate in the action of the complex verb.

In sentence (b) there are also two nouns represented by asterisks $(\mathrm{N})$ : the first one from the left is the indirect object directly c-commanded by PP and the second one is a direct non-specific object that follows the indirect object, lacks the particle ra and has to precede the non-verbal element within the CPr and be adjacent to it. Being bound by this adjacency principle, it cannot escape the domain of the complex predicate and has to remain a part of it. As in such constructions just one of the objects can participate in the action of the verb and the other one has become a part of the predicate, they cannot be regarded as locative constructions.

The results obtained from this study are consistent with the proposal presented by Rezai and Avand (2008) who believed Persian due to lacking the alternating forms of locative verbs is considered to be a more restricted language (subset language) compared with English (superset language). As it was mentioned before, Rezai and Avand provide no theoretical or syntactic evidence to explain the reason of this restriction in Persian. The findings of this study, however, are in contradiction with the attitudes of the majority of scholars studying Persian locative constructions (karimi Doostan and Safari (2011); Roshan (1998), etc...) as they believe that alternating forms also exist in Persian, although they may not be exactly equivalent with their English counterparts. The obtained results are in complete agreement with the theories and attitudes presented by Karimi (2005) about the basic word order and syntactic structure of Persian double object constructions.

\section{Summary and Conclusion}

Considering the syntactic evidence provided (Persian basic syntactic word order, syntactic and semantic features of specific and nonspecific object, and syntactic word formation process), it can be concluded that the structure Npx $\mathbf{N P z}$ (ra) NPy (bare noun) V, that was considered by Karimi Doostan and Safari (2011) to be the Persian counterpart of with variant in English is impossible, and consequently no alternating locative verbs are syntactically allowed in modern Persian. Therefore, locative verbs in Persian are either non-alternating figure verbs (e.g., Pašidan, spray) or non-alternating ground verbs (e.g., taziin kardan, decorate).

\section{Implications of the study}

Considering the fact that different languages have different alternation systems, it can be expected that the theoretical findings of this study could have pedagogical consequences for Persian native speakers and EFL teachers. Persian learners may experience difficulty when learning a language that its alternation system is different from Persian. Knowledge of the point that locative verbs do not alternate in Persian can help EFL teachers to predict the possible problems Persian EFL learners may be faced with when learning alternating locative constructions in a second or foreign language and to find remedies and appropriate instruction methods for teaching such constructions.

\section{References}

Bley_Vroman, R; Joo, H. R. (2001). The acquisition and interpretation of English locative constructions by native speakers of Korean. Studies in Second Language Acquisition, 23, 207-219.

Borer, H. (1994). The projection of arguments, University of Massachussettes Occasional Papers, 17, 19-47.

Goldberg, A. E. (1995). Constructions: A construction Grammar Approach to Argument Structure. Chicago, IL: University of Chicago Press

Halle, M; Marantz, A. (1993). Distributed morphology and the pieces of inflection. In Hale, K and Keyser, S (eds.), The View from Building 20 (111-176). Cambridge/London: The MIT Press.

Karimi Doostan, GH; Safari, A. (2011). Holistic reading in Persian locative alternation, Researches in Linguistics, 3(1), 77-100.

Karimi, S. (2003). Word Order and Scrambling. Oxford/Berlin: Blackwell Publishers.

Karimi, S. (2005). A Minimalist Approach to Scrambling: Evidence from Persian. Berlin: Mouton de Gruyter.

Levin, B. and M. Rappaport (1988). Non-event --er nominals: a probe into argument structure, Linguistics, 26, 10671083.

Levin, B; Raappaport, M. (2005). Argument Realization. Cambridge: Cambridge University Press.

Marantz, A. (1997). A Theory of Grammatical Relations. Unpublished Ph.D. dissertation, Massachusetts Institute of Technology.

Mohammad, J; Karimi, S. (1992). Light verbs are taking over: complex verbs in Persian. The Proceedings of Western Conference on Linguistics, 5, 195-212.

Olbishevska, O. (2005). Locative Alternation in Slavic: The Role of Prefixes. The 2004 Annual Conference of the Canadian Linguistic Association.

Rezai, M, J; Avand, S. (2008). The acquisition of English locative constructions by Persian speakers: Syntax-semantic interface. Iranian EFL Journal, 3 (1), 255-274.

Tenny, C. (1987). Grammaticalizing Aspect and Affectedness. Doctoral Dissertation. MIT, Cambridge, MA.

Van Hout, A. (1996). Event Semantics of Verb Frame Alternations. TILDIL Dissertation Series. 